\title{
Strength Analysis of a Two-Layer PETF-Concrete Column with Allowance for Contact Interaction between Layers
}

\author{
Andrii Velychkovych $\mathbb{D D}^{1}{ }^{1}$ Liubomyr Ropyak, $^{2}$ and Olga Dubei ${ }^{3}$ \\ ${ }^{1}$ Department of Construction and Civil Engineering, Ivano-Frankivsk National Technical University of Oil and Gas, \\ 15 Karpatska Street, Ivano-Frankivsk 76019, Ukraine \\ ${ }^{2}$ Department of Computerized Engineering, Ivano-Frankivsk National Technical University of Oil and Gas, 15 Karpatska Street, \\ Ivano-Frankivsk 76019, Ukraine \\ ${ }^{3}$ Oil and Gas Production Department, Ivano-Frankivsk National Technical University of Oil and Gas, 15 Karpatska Street, \\ Ivano-Frankivsk 76019, Ukraine
}

Correspondence should be addressed to Andrii Velychkovych; a_velychkovych@ukr.net

Received 12 May 2021; Revised 6 September 2021; Accepted 14 September 2021; Published 23 September 2021

Academic Editor: Francesco Colangelo

Copyright (C) 2021 Andrii Velychkovych et al. This is an open access article distributed under the Creative Commons Attribution License, which permits unrestricted use, distribution, and reproduction in any medium, provided the original work is properly cited.

\begin{abstract}
This article develops an idea of mechanical recycling of polymer wastes. Unlike previous research studies, which are dedicated to the study of the physical and mechanical properties of fibrous concrete and the technology of its manufacturing, this work considers a specific construction product-laminated concrete column made of recycled polyethylene terephthalate (PETF). Currently, there are no policy documents (standards or codes) regarding the engineering design of such constructions. Therefore, the authors' attention is focused on mechanical and mathematical modeling of the laminated column behavior under operational load. An analytical study of two-layer PETF-concrete column's stress-strain state was performed, taking into account the contact interaction between inhomogeneous layers of the materials. It has been determined that, in certain circumstances, the contact pressure between the layers can have a significant effect on the load-bearing capacity of the column. In general, a method of engineering assessment of laminated columns' load-bearing capacity was developed.
\end{abstract}

\section{Introduction}

Today, the disposal of polymer waste has become a major environmental problem over the world. In particular, accumulation of polyethylene terephthalate (PETF) wastes from single-use bottles for drinking water threatens seriously the environment. There are several basic ways to recycle the aforementioned wastes: reuse, mechanical processing, chemical processing, and incineration for electricity generation. One of the possible solutions to the problem is adding premilled polymer wastes to cement-sand mixtures to replace part of the natural aggregate [1]. For offshore platforms, bridges, and engineering constructions, such use of polymer wastes is a cost-effective and environmentally friendly solution.

Previous studies have shown the feasibility of introducing polymer waste into concrete mixtures to improve their physical and mechanical properties [2, 3]. The technology of polymer household waste utilization by their mechanical recycling has been developed. Optimal sizes of polymer fillers, their quantity, necessary mixing time, and concrete-mix vibration were specified [4-6]. The obtained PETF concrete is a composite material consisting of a concrete matrix (usually fine-grained) with uniform discrete particles of the polymeric filler chaotically distributed in its volume. Such dispersed reinforcement improves the mechanical characteristics of concretes: increases the axial tensile strength and transverse strength in addition to increasing the crack resistance, wear resistance, etc. [7].

In general, modern fiber concrete allows you to reduce or replace steel rods (steel reinforcement) for concrete reinforcement. Steel fiber is the most widely used material for structural fiber concrete production. However, plastic fibers are a good alternative to steel fibers, due to their main 
advantages such as chemical stability, less weight for similar residual strength of concrete, low cost, and prevention of cracking in concrete. In addition, plastic fibers have additional advantages [8-10]:

(1) Easy distribution of PETF fibers in the mixture provides a uniform three-dimensional structure of concrete.

(2) Low weight for transportation and storage; the scope of tasks aims at analytical prediction of such elements behavior depending on the characteristics and the quantitative ratio of the PETF-concrete components, and it is very relevant due to the current environmental situation.

(3) PETF filler does not cause magnetic interference; such concrete products can be used, for example, in structures associated with the construction of hospitals or warehouses with the possibility of automated storage of products.

(4) PETF fiber reinforced concrete better resists vibration and shock loads and has better sound insulation properties.

Application of PETF concrete allows using construction solutions more effectively than conventional reinforcement and decreases material consumption, reducing the weight and cost of parts for buildings and constructions $[8,9]$.

The scope of tasks aims at analytical prediction of such elements behavior depending on the characteristics and the quantitative ratio of the PETF-concrete components, and this is very relevant due to current environmental situation. Their solution will provide the design optimization of PETFconcrete constructions and reduce the expensive experimental works.

The problems mentioned above, as well as the lack of commonly used engineering techniques (codes or standards) for calculating the load-bearing capacity of laminated structures containing PETF concrete, were the main motivation of our study.

\section{Analysis of Literature Sources: The Purpose of Study}

Today, the behavior of traditionally designed columns regarding axial strength, axial and transverse displacement, cracking scheme, failure modes, and so on has been studied in detail $[11,12]$.

Studies on fiber concrete mechanical characteristics prediction, in particular PETF concrete, depending on the quantitative and qualitative characteristics of its components, are widely presented in the scientific world $[3,13,14]$.

In particular, the effect of plastic waste accumulation on the mechanical and thermophysical properties of concrete was studied in [15]. The works [16,17] studied the possibility of PET waste chemical processing and their application for polymer concrete production. Recycled plastic waste was depolymerized by glycolysis to obtain an unsaturated polyester resin, which was used to prepare cement paste. The mentioned works also compared the technical characteristics of ordinary concrete and concrete with PET filler.
Modern stone columns are often prone to cracking due to possible overloads. Moreover, their fragility during earthquakes is of particular concern in earthquake-prone regions. To reduce this design flaw, some researchers suggest reinforcing stone columns with polymer fibers [18]. The work [19] presents experimental studies of the behavior of such columns under the action of axial loads.

In recent years, constructions of laminated, mostly twolayered, coatings have become popular. Often, the layers consist of heavy concrete and effective fibrous concrete. Such constructions have been widely implemented in road and airfield pavements, heavy loaded floors of industrial buildings, and so on [20]. Such constructions are assumed to increase strength, crack resistance, and stiffness of bearing systems, as well as improve other important operational properties of them: water resistance, freeze resistance, and wearing [7].

Traditionally, multilayered constructions in the building industry are load-bearing and non-load-bearing walls, interfloor coverings, and elements of combined floors (walkways, rafters, beams, and trusses).

The specifics of the studied two-layer column considered as a laminated system for a proper design calculation consist of bearing capacity of both layers. Thus, there is a need to solve the contact interaction problem between the concrete core and the shell of PETF concrete.

Strength and stiffness calculations for laminated structures under axisymmetric loads are presented in works $[21,22]$ and those under the actions of local arbitrarily oriented loads are presented in works [23-25]. In order to study the behavior of materials under load, including the composition of laminated structures, physical [26], experimental [27], electrochemical [28, 29], and analytical [30] methods were used.

When setting contact problems, researchers pay considerable attention to modeling the strength, stiffness, and stability of shell and plate structures [31,32], especially of asymmetrical and complex shapes [33], as well as in the presence of stress concentrators [34-36]. In particular, the effects of stress concentration in inhomogeneous solids near cavities and vicarious particulates have been studied in works [37-39]. Studies of contact interaction between a cylindrical shell and an elastic body by virtual and laboratory experiments are presented in works [40, 41]. The works $[42,43]$ considered the two fracture mechanisms: cracking of the plate near the peak of a slit and breach of filler integrity. The first is described by the criterion of the linear mechanics of fracture, and the second one is described by the classical theory of strength.

Another approach is also possible to model modern multilayer constructions. Some researchers present them as heterogeneous structures with averaged physico-mechanical properties [44, 45]. However, if the layers of such constructions contain technological and structural concentrators, especially defects or inclusions, then the solution of the boundary problems of the elastic theory is significantly complicated. There are no effective analytical methods to evaluate comprehensively the stress-strain state and the boundary state for such structures. Usually, researchers try 
to solve such problems using software packages based on the finite element method. In particular, modern methods of virtual experiment for the behavior study of heterogeneous structures are considered in work [46]. Numerical methods for formulating and solving contact problems on the interaction of rigid deformable bodies with rocks are presented in $[47,48]$.

Despite the existence of different methodologies, methods, and approaches for assessing the strength of laminated structures, there are currently no generally acknowledged engineering techniques (codes, standards, or other policy documents) for calculating the bearing capacity of two-layer columns, manufactured using disposable polymeric filler.

The purpose of this study is to reveal the basic regularities of the stress-strain state of the laminated column based on the fundamental analytical analysis, performed by means of deformable body mechanics. As a result, an engineering technique will be developed to calculate the loadbearing capacity of laminated columns, which will take into account the influence of contact interaction between inhomogeneous layers of the material on the column strength.

\section{Mechanical-Mathematical Model of a Two- Layer Concrete Column considering the Contact Interaction between Layers}

The two-layer concrete column, which consists of the concrete core and the shell of light PETF concrete, is presented as a sectionally homogeneous design model. Let us consider a cylindrical body 1 with a through hole (Figure 1) smoothly rested upon a rigid barrier. The thickness of its vertical wall is $h$, and the outer diameter is $D$. The hole's cavity is tightly filled with an elastic deformable cylinder (2) with characteristic linear dimensions: radius $R$ and height $a$. Between the outer surface of the cylinder (2) and the inner surface of the hole of the body (1), there are bilateral constraints. The shell material of light PETF concrete is modeled as a continuous isotropic medium with averaged elasticity and strength constants. The upper end of the column is represented by a flat smooth platform. The external load $Q$ is considered to be applied to the upper end of the column through a rigid stamp. The average pressure under the stamp is $p=Q /\left(F+F_{0}\right)$, where $F$ is the cross-sectional area of the column's concrete core and $F_{0}$ is the cross-sectional area of the column's outer layer of PETF concrete.

The geometrical and physico-mechanical parameters of the column are assumed to be of such values that by default its flexibility is small, so the effects of columnar deflection are neglected. The strain-stress state of the described system is analyzed in cylindrical coordinates.

The elastic equilibrium of a cylindrical body (1) is described by the equations of the momentless theory of shells. The static equilibrium of the outer layer of the column is described by the following equation:

$$
\begin{aligned}
& h \frac{\mathrm{d} \sigma_{z 0}}{\mathrm{~d} z}-\tau=0, \\
& h \sigma_{\beta 0}=-R \sigma,
\end{aligned}
$$

and the behavior of PETF concrete, influenced by external loads, is described by physical relations (generalized Hooke's law):

$$
\begin{aligned}
& \varepsilon_{z 0}=\frac{1}{E_{0}}\left(\sigma_{z 0}-\mu_{0} \sigma_{\beta 0}\right), \\
& \varepsilon_{\beta 0}=\frac{1}{E_{0}}\left(\sigma_{\beta 0}-\mu_{0} \sigma_{z 0}\right),
\end{aligned}
$$

and Cauchy relation:

$$
\begin{aligned}
& \varepsilon_{z 0}=\frac{\mathrm{d} u_{0}}{\mathrm{~d} z}, \\
& \varepsilon_{\beta 0}=\frac{w_{0}}{R},
\end{aligned}
$$

where $\sigma_{z 0}, \sigma_{\beta 0}$ are stresses; $\varepsilon_{z 0}, \varepsilon_{\beta 0}$ are deformations of the outer layer of PETF concrete in the axial and circular directions, respectively; $\sigma, \tau$ are normal and tangential contact stresses; $u_{0}, w_{0}$ are axial and radial displacements; and $E_{0}, \mu_{0}$ represent averaged Young's modulus and Poisson's ratio of PETF concrete.

The initial model relations for the inner cylinder (2) (column's concrete core model) will be the following equilibrium equations $[49,50]$ :

$$
\begin{aligned}
& \frac{\mathrm{d} \sigma_{z}}{\mathrm{~d} z}+\frac{2 \tau}{R}=0, \\
& \sigma_{r}=\sigma_{\beta}=\sigma .
\end{aligned}
$$

Hooke's law:

$$
\begin{aligned}
& \varepsilon_{z}=\frac{1}{E}\left(\sigma_{z}-\mu\left(\sigma_{r}+\sigma_{\beta}\right)\right), \\
& \varepsilon_{\beta}=\frac{1}{E}\left(\sigma_{\beta}-\mu\left(\sigma_{r}+\sigma_{z}\right)\right),
\end{aligned}
$$

and Cauchy relation:

$$
\begin{aligned}
& \varepsilon_{z}=\frac{\mathrm{d} u}{\mathrm{~d} z}, \\
& \varepsilon_{\beta}=\frac{w}{R},
\end{aligned}
$$

where $\sigma_{r}, \sigma_{\beta}, \sigma_{z}$ are radial, circular, and axial stresses in the concrete core of the column; $\varepsilon_{z}, \varepsilon_{\beta}$ are deformations of the core, respectively, in the axial and circular directions; $u, w$ are axial and radial displacements; and $E, \mu$ represent elasticity moduli of concrete.

The contact interaction of the PETF concrete shell and the concrete core of the two-layer column is described by the perfect contact relations $u_{0}=u, w_{0}=w$. When developing the calculation model, we assume that the radial displacement of the concrete core's outer surface $w$ is equal to PETFconcrete shell's inner surface $w_{0}$, namely, $w_{0}=w$ (in other words, there is no sticking of contact surfaces). We also assume that there is no slippage on the contact surfaces, i.e., the corresponding axial displacements $u_{0}=u$. The equality conditions of axial $u_{0}=u$ and radial $w_{0}=w$ displacements 


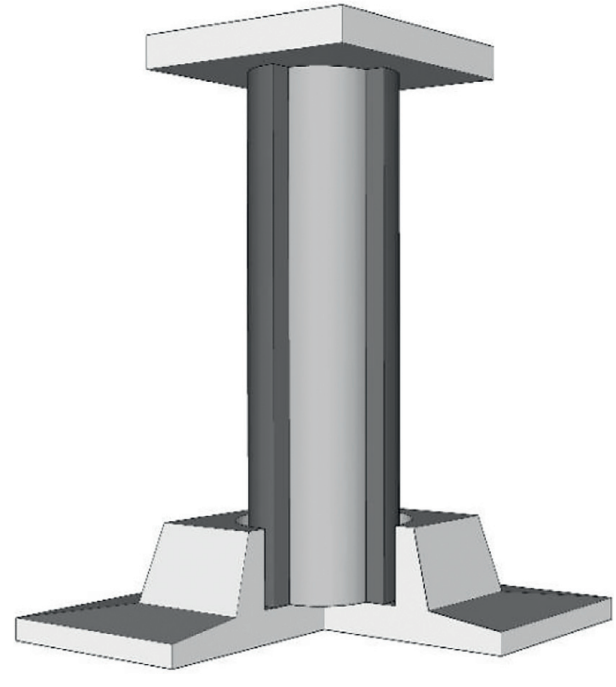

(a)

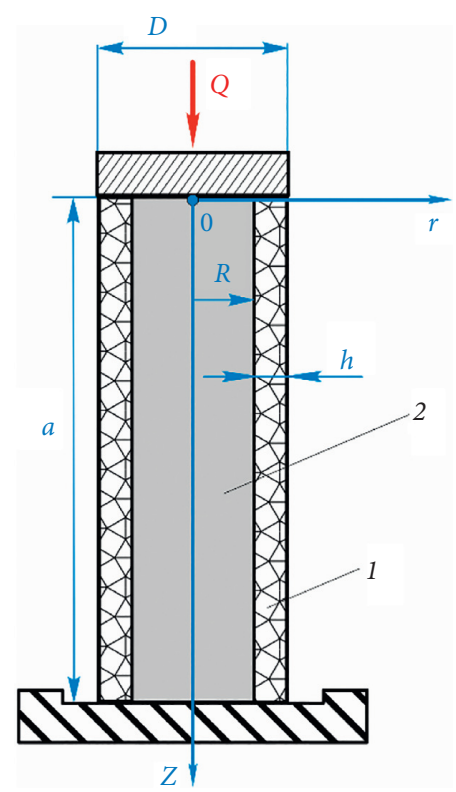

(b)

Figure 1: Scheme of two-layer concrete column: (a) general view; (b) design scheme (1-shell of light PETF concrete; 2-concrete core).

are replaced by the compatibility conditions of the corresponding deformations of the shell and the core.

For the end of the two-layer column, the boundary condition is fulfilled:

$$
\sigma_{z}(0) F+\sigma_{z 0}(0) F_{0}+Q=0 .
$$

\section{Determination of the Stress State Components of the Two-Layer Column ("Light PETF Concrete-Concrete Core" System)}

The main components of the stress state of the two-layer column are the aforementioned stresses $\sigma_{z 0}, \sigma_{\beta 0}, \sigma_{r}, \sigma_{\beta}, \sigma_{z}, \sigma$, $\tau$.

To find them, we equate the right sides of relations (3) and (8), as well as (4) and (9), and take into account equations (1), (2), (6), and (7). As a result, we obtain a system of manageable equations for finding the stress state components of the two-layer column:

$$
\left\{\begin{array}{l}
h \sigma_{\beta 0}=-R \sigma \\
\sigma_{r}=\sigma, \sigma_{\beta}=\sigma, \tau=0, \\
\frac{1}{E} \sigma_{z}-\frac{1}{E_{0}} \sigma_{z 0}-\left(\frac{2 \mu}{E}+\frac{\mu_{0}}{E_{0}} \frac{R}{h}\right) \sigma=0, \\
-\frac{\mu}{E} \sigma_{z}+\frac{\mu_{0}}{E_{0}} \sigma_{z 0}+\left(\frac{1}{E_{0}} \frac{R}{h}+\frac{1-\mu}{E}\right) \sigma=0 .
\end{array}\right.
$$

Solving the system of (11) together with boundary condition (10), all components of the stress state are found. The main analytical results are presented below.
Axial stresses in the concrete core material:

$$
\sigma_{z}=-\frac{Q}{F_{0}} \chi
$$

where

$$
\begin{aligned}
& \chi=\frac{1 / E_{0}\left(\psi-\mu_{0}\right)}{1 / E(\psi-\mu)+1 / E_{0} F / F_{0}\left(\psi-\mu_{0}\right)}, \\
& \psi=\frac{2 E F / F_{0}+(1-\mu) E_{0}}{2\left(\mu E_{0}+\mu_{0} E F / F_{0}\right)} .
\end{aligned}
$$

Axial stresses in the outer layer of the column:

$$
\sigma_{z 0}=-\frac{Q}{F_{0}}\left(1-\frac{F}{F_{0}} \chi\right) \text {. }
$$

Normal stress in the contact surfaces of the concrete core and light PETF-concrete shell:

$$
\sigma=\frac{Q}{2 F / E_{0}+(1-\mu) F_{0} / E}\left(\frac{\mu_{0}}{E_{0}}-\chi\left(\frac{\mu}{E}+\frac{\mu_{0}}{E_{0}} \frac{F}{F_{0}}\right)\right) .
$$

Hoop stress in the material of the PETF-concrete shell:

$$
\sigma_{\beta 0}=-2 \sigma \frac{F}{F_{0}} .
$$

\section{Evaluation of the Two-Layer Column's Strength}

Almost all the materials of the two-layer column are in a complex stress state. The points of the column's concrete core are in three-dimensional stress state due to axial $\left(\sigma_{z}\right)$, circular $\left(\sigma_{\beta}\right)$, and contact $(\sigma)$ stresses. Using the stress 
intensity criterion, the concrete core strength model is presented as follows:

$$
\frac{\sigma_{u}}{\sigma_{\mathrm{eq}}}=\frac{\sigma_{u}}{\sqrt{\sigma_{z}^{2}+\sigma_{\beta}^{2}+\sigma^{2}-\sigma_{z} \sigma_{\beta}-\sigma_{\beta} \sigma-\sigma_{z} \sigma}} \geq[n],
$$

where $\sigma_{u}$ is the ultimate strength of concrete; $\sigma_{e q}$ represent the maximum equivalent stresses in the core of the column; and $[n]$ is the admissible value of the strength margin according to stresses.

Depending on the geometrical and physico-mechanical parameters of the two-layer column, points on the inner (for $r=R$ ) or outer (for $r=R+h$ ) surfaces can turn out to be dangerous in the shell of light PETF concrete. Three-dimensional stress state arises under the action of axial, circular, and contact stresses on the inner surface of the shell. A two-dimensional stress state occurs on the outer surface-here the contact stresses are equal to zero. Using the stress intensity criterion, the strength model of the PETFconcrete shell is

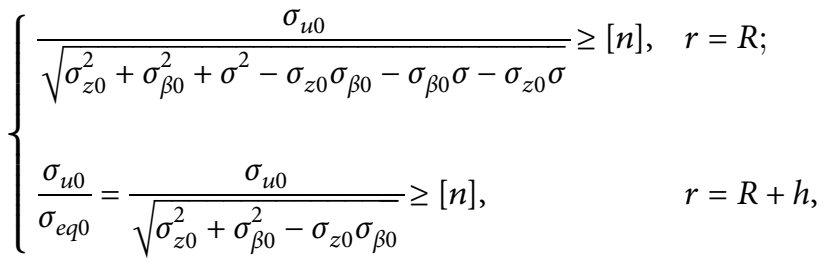

where $\sigma_{u 0}$ is the ultimate strength of light PETF concrete and $\sigma_{e q 0}$ represent the maximum equivalent stresses in the layer of PETF concrete.

For formalized strength assessment of a two-layer concrete column, it is necessary to check the fulfilment of all three inequalities (17) and (18).

\section{The Results of the Stress State Study of the Two-Layer Concrete Column}

Let us illustrate the analytical results obtained for a specific practical case. Let the column's concrete core be made of concrete grade M 300 (class B 22.5) with an average compressive resistance $\sigma_{u}=28.9 \mathrm{MPa}$, modulus of elasticity $E=27 \mathrm{GPa}$, and Poisson's ratio $\mu=0.21$. For the shell of light PETF concrete, three variants were considered, which differ only in the amount of reinforcing filler-polyethylene terephthalate $(4 \%, 10 \%$, and $15 \%$ of the total mass of the mixture). We have specified the amount of reinforcing filler based on the results of previous experimental studies. These filler values are the characteristic levels of reinforcement in the vicinity of which there are significant changes in the mechanical characteristics of PETF concrete to be investigated by a classical compression experiment. The tests showed a significant reduction in the strength limit when using levels of reinforcement of PETF concrete higher than $15 \%$. Therefore, we decided that it is not appropriate to apply a level of reinforcement higher than $15 \%$ for the column as a whole. The required physical and mechanical characteristics of such PETF concrete are given in Table $1[51,52]$.
The analysis results of behavior of the two-layer column under the action of compressive loads are presented in dimensionless form, because in this case, one resolved dimensionless variant corresponds to the whole group of possible dimensional tasks. For this purpose, a dimensionless lamination factor was used: $k=F /\left(F+F_{0}\right)$-the ratio of the cross-sectional area of the concrete core to the total cross-sectional area of the column. The greater the thickness of the outer shell of the PETF concrete, the lower $k$, under the same conditions.

Figure 2 shows the influence of the axial stresses in the material of the two-layer concrete column on the lamination factor. Hereafter, the curves are indicated by the following: 1-a column, where PETF-concrete layer has $4 \%$ of reinforcing filler; 2-a column, where PETF-concrete layer has $10 \%$ of reinforcing filler; and 3-a column, where PETFconcrete layer has $15 \%$ of reinforcing filler.

Figure 2(a) clearly indicates that the stiffer the material used to cover the column, the greater the portion of the external axial load it perceives. Figure 2(b) shows that the stiffer PETF concrete is used for the outer layer of the column; the less load accounts for the concrete core.

(1) For a tubular column made of PETF concrete in the absence of a core $(E \longrightarrow 0$ and $\mu \longrightarrow 0)$, we obtain $\sigma_{z 0}=-Q / F_{0}$.

(2) For a homogeneous column $E=E_{0}$ and $\mu=\mu_{0}$, we obtain $\sigma_{z 0} / p=\sigma_{z} / p=-1$.

(3) If $k \longrightarrow 0$, which also corresponds to a homogeneous column, $\sigma_{z 0} / p=\sigma_{z} / p=-1$.

Due to the fact the Poisson's ratios for the core material of the column and the material of its outer layer are different, there will be contact stresses (contact pressure) between the core and the outer layer during operation. This contact pressure causes ring stresses and hoop stresses in the outer layer of the column.

Figure 3 shows the dependency of contact stress between the concrete core and the layer of PETF concrete on the lamination factor of the column. When using all three variants of PETF concrete, contact stresses turned out to be negative, that is, compressive. Further analysis of formula (15) shows the following:

(1) If materials with $\mu<\mu_{0}$ are used to construct the twolayer concrete column, contact stresses will change their sign-they will become tensile, which may lead to poor adhesion or even tearing between layers.

(2) For a homogeneous column $E=E_{0}$ and $\mu=\mu_{0}$, we obtain $\sigma=0$.

If the lamination factor of the column increases, the contact stresses between the concrete core and the PETFconcrete shell gradually decrease. The rate of such decreasing depends on the amount of polyethylene terephthalate in the shell material. The higher the percentage of the reinforcing filler in the layer of PETF concrete, the faster the contact stresses decrease with increasing of $k$. 
TABle 1: Physical and mechanical characteristics of PETF concrete.

\begin{tabular}{lcccc}
\hline No. & Amount of reinforcing filler $(\%)$ & Compressive resistance, $\sigma_{u 0}(\mathrm{MPa})$ & Modulus of elasticity, $E_{0}(\mathrm{GPa})$ & Poisson's ratio, $\mu$ \\
\hline 1 & 4 & 29.3 & 19.0 & 0.19 \\
2 & 10 & 15.9 & 14.0 & 0.16 \\
3 & 15 & 7.1 & 11.5 & 0.15 \\
4 & 0 & 28.9 & 27.0 & 0.21 \\
\hline
\end{tabular}

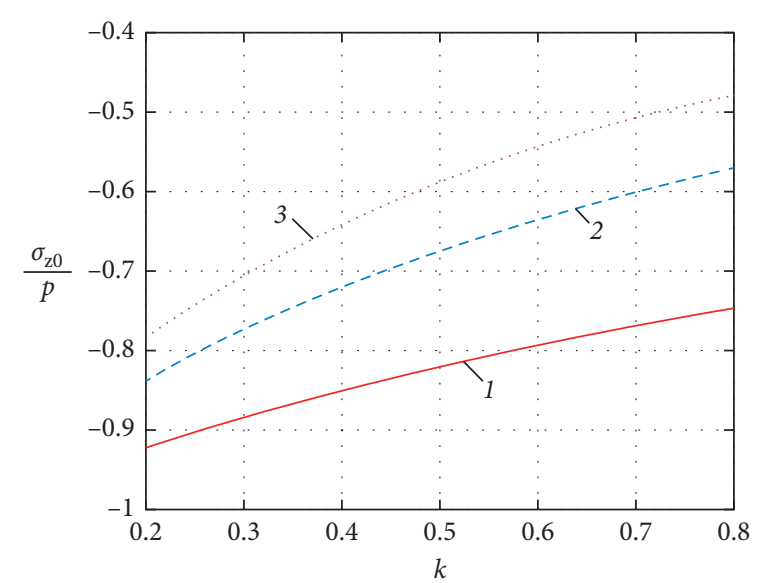

(a)

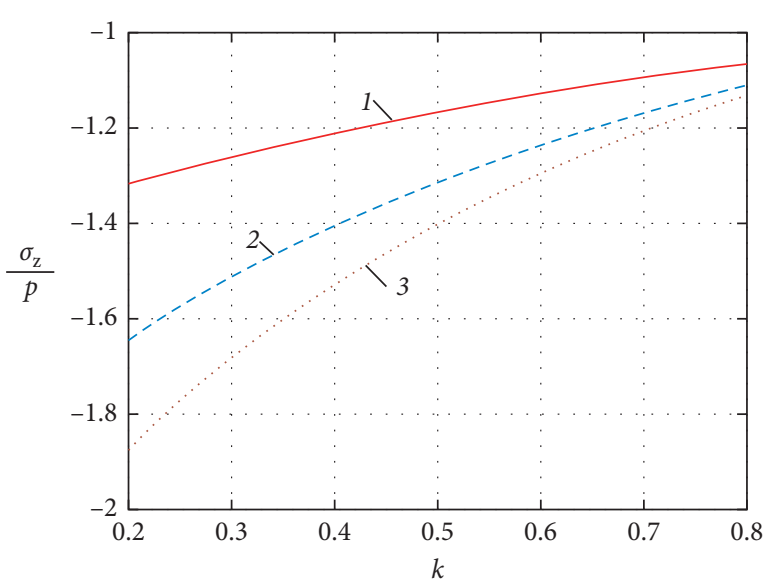

(b)

FIgURe 2: Axial stresses in two-layer concrete column: (a) stress in the layer of PETF concrete; (b) stress in the concrete core.

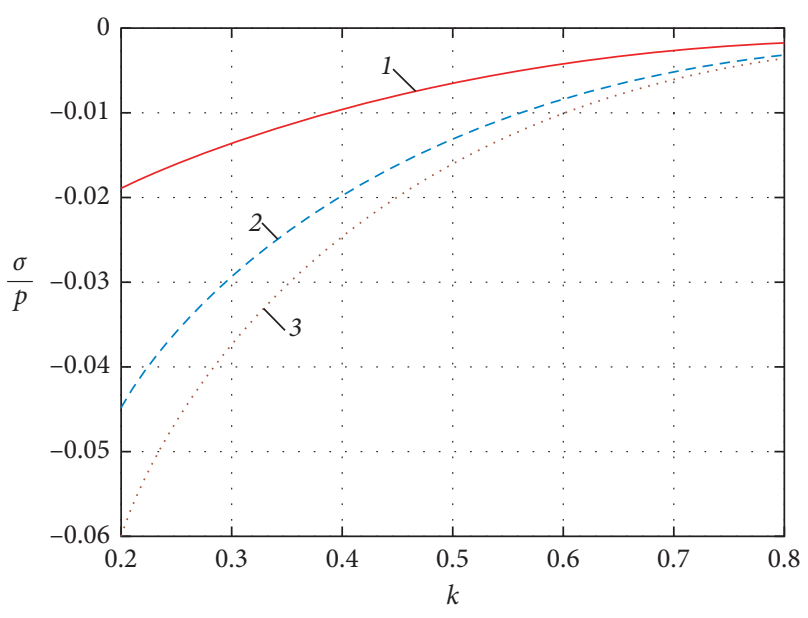

FIgURE 3: Contact stresses between layers of the column.

Figure 4 shows the influence of hoop stresses in the PETF-concrete shell on the column lamination factor. These tensions turned out to be positive, that is, tensile. For the considered variants of PETF concrete, the following was observed: with the increase of factor $k$ (that is, with the decrease of layer thickness $h$ ), hoop stresses first increase, reach extrema, and then gradually decrease.

Materials of the two-layer concrete column, when it is loaded, are in a complex stress state. Therefore, one of the strength theories should be used for strength assessment, and evaluation is carried out based on the maximum equivalent stresses in the shell $\left(\sigma_{\text {eq0 }}\right)$ and the core $\left(\sigma_{\text {eq }}\right)$ of the column. To find them, we used the stress intensity criterion ((15) and (16)).

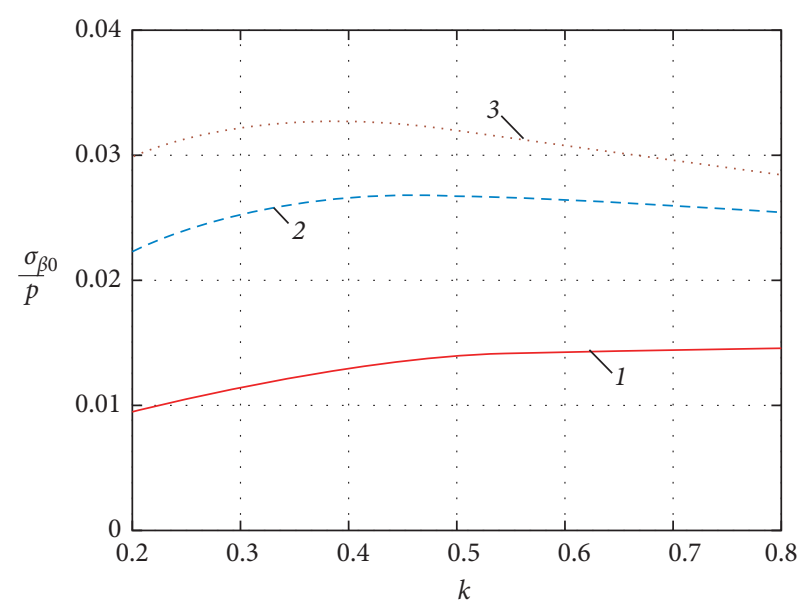

FIgURE 4: Hoop stresses in a layer of PETF concrete.

Figure 5 shows the influence of the maximum equivalent stresses in the two-layer column on the lamination factor. If equivalent stresses do not exceed the admissible values (determined experimentally), the strength of the column will be ensured.

Here is an evaluation example of the bearing capacity of the particular concrete column. The light PETF concrete with $15 \%$ of reinforcing filler was used to construct the column. The two-layer column (Figure 1) has a diameter $D=0.5 \mathrm{~m}$, and the thickness of the PETF-concrete layer $h=0.1 \mathrm{~m}$. The admissible value of the strength margin according to stresses, taking into account all possible factors that consider the operation specifics of the column, is $[n]=2.5$. Permissible load on the column must be determined. 


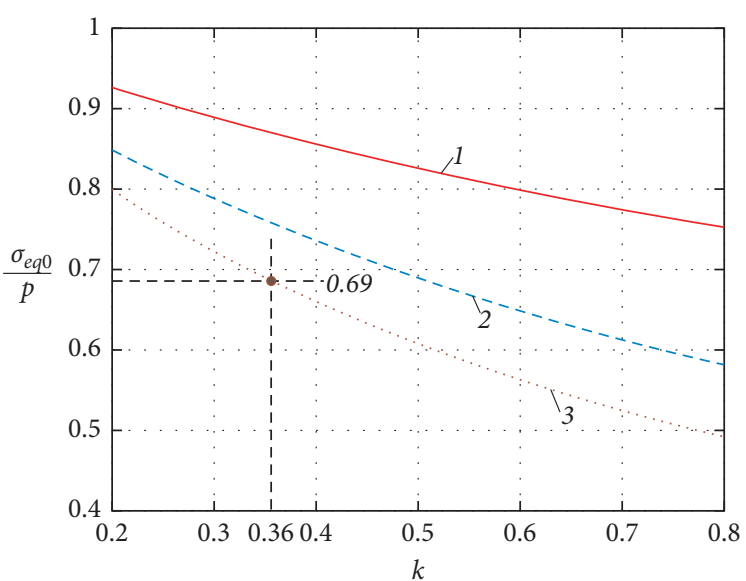

(a)

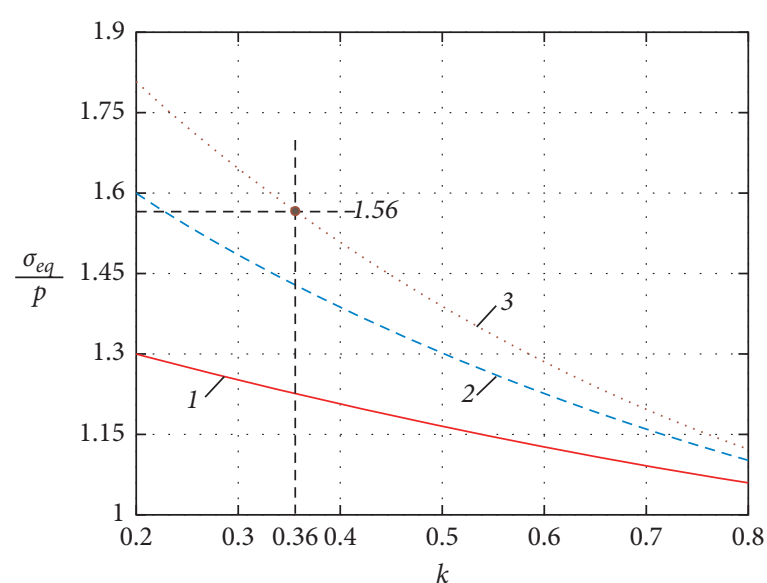

(b)

FIgURE 5: Equivalent stresses in the two-layer column: (a) stress in the layer of PETF concrete; (b) stress in the concrete core.

Lamination factor of such column:

$$
k=\frac{F}{F+F_{0}}=\frac{(D-2 h)^{2}}{D^{2}}=\frac{(0,5-2 \cdot 0,1)^{2}}{0,5^{2}}=0,36 .
$$

For such value of factor $k$, from the influence given in Figure 5, we find the maximum equivalent stresses:

$$
\begin{aligned}
\sigma_{\text {eq } 0} & =0,69 p, \\
\sigma_{\text {eq }} & =1,56 p .
\end{aligned}
$$

After substituting (18) into (16) and (17) and considering that $p=4 Q / \pi D^{2}$, we obtain

$$
\left\{\begin{array}{l}
\frac{\sigma_{u}}{1,56 p}=0,503 \frac{D^{2}}{Q} \sigma_{u} \geq[n] ; \\
\frac{\sigma_{u 0}}{0,69 p}=1,14 \frac{D^{2}}{Q} \sigma_{u 0} \geq[n],
\end{array}\right.
$$

where $[Q]=\min Q=0.81 \mathrm{MN}$. Therefore, the maximum load that can be safely applied to a given two-layer concrete column is $0.81 \mathrm{MN}$.

\section{Discussion}

Let us briefly formulate the main theses of the research results:

(1) Polymer wastes if not recycled become a serious threat to the environment.

(2) Utilization of polymer wastes is possible-they can be used for improving properties of laminated constructions.

(3) An engineering technique is presented for calculating the load-bearing capacity of laminated columns, which are made using a recycled polymeric filler.

(4) A method of calculating the bearing capacity of laminated columns, which takes into account the influence of contact interaction between inhomogeneous layers of the material on the strength of the column, is proposed.

We would like to describe in detail the peculiarities of the authors' approach to modeling the contact interaction between inhomogeneous layers in a two-component column. When developing the calculation model, we assume an ideal two-way mechanical contact on the interface of the concrete core and the shell of PETF concrete. This means the continuity of radial and axial displacements and the continuity of normal radial and tangential axial stresses between layers of the column. Physically, this means no slippage and separation on the contact surface. Annular displacements and corresponding tangential stresses are absent due to the axial symmetry of the problem. We changed the conditions of radial and axial displacement continuity by the conditions of compatibility of the corresponding deformations on the contact surface of the shell and the core. Despite the compatibility of deformations, the axial and annular normal stresses (and hence equivalent stresses) in the concrete core and the shell of PETF concrete are different. This is because the shell and core materials have different physical and mechanical properties, including different Young's moduli and Poisson's ratios.

Regarding our hypotheses, the following should be noted.

(1) Known studies indicate that compliance with technological standards of production provides a high level of adhesion of layered systems made of cement composites, as well as contact surfaces formed by concrete of different brands (for example, [53, 54]).

(2) The results of our calculations showed that the radial stress between the compressed concrete core and the shell of PETF concrete is always negative, i.e., compressive. Therefore, for the cases we have considered, there is really no adhesion violation.

(3) If we change the conditions of one-sided interaction of the surfaces of the concrete core and the shell of PETF concrete, presenting them in the form of contact 
inequalities (i.e., assuming the possibility of zones of adhesion, separation, and slip), we would get a generally nonlinear problem, for the solution of which it is necessary to implement an iterative process. Taking the research carried out by us as the first step of iteration, we are convinced that $\sigma<0$ (contact stresses are compressive) for the coupling surface of a compressed two-component column, i.e., there is no separation of contact surfaces. Thus, the presented results will also be a solution of a non-linear contact problem.

Analysis of the results of the solved contact problem showed the following. If the lamination factor $k$ of the column increases, the contact stresses $\sigma$ between the concrete core and the PETF-concrete shell gradually decrease. The rate of such decrease depends on the amount of polyethylene terephthalate in the shell material. The higher the percentage of the reinforcing filler in the layer of PETF concrete is, the faster $\sigma$ decreases with increasing $k$. The presence of contact stresses between the layers of the column leads to the appearance of hoop stresses $\sigma_{\beta 0}$ in the shell of PETF concrete. For all analyzed cases, $\sigma_{\beta 0}$ stresses were positive, i.e., tensile. Trends of hoop stress change associated with increasing $k$ are more complex than changes of contact stresses. The following is observed for the considered types of PETF concrete: if $k$ increases, then the hoop stresses first increase, acquire an extreme, and then gradually decrease. The correspondence between the lamination factor of the column associated with the extreme hoop stresses in the outer layer and the content of reinforcing filler in PETF concrete is as follows: $k=0.76$ at the filler content of $4 \%$; $k=0.49$ at the filler content of $10 \%$; and $k=0.36$ at the filler content of $15 \%$. When designing two-component columns, a combination of the aforementioned parameters should be avoided to prevent the occurrence of extreme values of hoop stresses in the outer layer of the column.

In order to verify the obtained analytical results, we performed modeling tests of the filled container (PET container filled with compacted sandy soil). The process of loading was carried out through a massive plate mounted on the cover of the filled container. The tests were performed using a universal test machine equipped with an automated measuring system (ASTM-Digital). The load $Q$ to the cover ranged from 0 to $1000 \mathrm{kN}$. The least squares method was used to process the obtained experimental data. The load was carried out until visually noticeable destruction of the container (the formation of a barrel-shaped container or a crack). The discrepancy between the analytical results and the results of the experiment was within $12 \%$.

This article develops an idea of mechanical recycling of polymer wastes. Unlike previous research studies, in this work, a specific construction product-laminated concrete column that is made using recycled polyethylene terephthalate-is considered. The authors' attention is focused on mechanical and mathematical modeling of the behavior of the laminated column under the influence of operational load. An analytical study of the stress-strain state of a two-layer PETF-concrete column was performed, taking into account the contact interaction between inhomogeneous layers of the material. The final evaluation of the laminated column strength was carried out based on the energy criterion, and it revealed that the contact pressure between the layers can have a significant effect on its loadbearing capacity.

\section{Conclusions}

The performed research develops ideas of ecological recycling technologies, in particular, the idea of mechanical recycling of polymer wastes. The specific product of the building industry is considered in this work-the two-layer concrete column, one layer of which is manufactured using dispersed reinforcement of concrete by utilizing polyethylene terephthalate. Currently, there are no generally acknowledged engineering techniques (codes and standards) to calculate the loadbearing capacity of laminated columns, which are made using the recycled polymeric filler. The findings of the study should help in filling this theoretical gap.

Based on fundamental analytical analysis, carried out by means of deformable body mechanics, the basic regularities of the stress-strain state of the laminated column under the influence of operational load are revealed. The final estimation of the column's strength was accomplished by the energy criterion of Huber-von Mises, and it was determined that the contact stresses, which occur between inhomogeneous layers of the material, can have a significant influence on the bearing capacity of the column.

In general, the article develops an engineering method of calculating the bearing capacity of laminated columns, which takes into account the influence of contact interaction between inhomogeneous layers of the material on the strength of the column.

\section{Data Availability}

The data used to support the findings of this study are available from the corresponding author upon request.

\section{Conflicts of Interest}

The authors declare that they have no conflicts of interest.

\section{References}

[1] I. H. Alfahdawi, S. A. Osman, R. Hamid, and A. I. Al-Hadithi, "Influence of PET wastes on the environment and high strength concrete properties exposed to high temperatures," Construction and Building Materials, vol. 225, pp. 358-370, 2019.

[2] J. Tamrin and J. Nurdiana, "The effect of Recycled HDPE Plastic Additions on Concrete Performance," Recycling, vol. 6, no. 1, p. 18, 2021.

[3] Z. H. Lee, S. C. Paul, S. Y. Kong, S. Susilawati, and X. Yang, "Modification of Waste Aggregate PET for Improving the Concrete Properties," Advances in Civil Engineering, vol. 2019, no. 1, 10 pages, Article ID 6942052, 2019.

[4] L. Gu and T. Ozbakkaloglu, "Use of Recycled Plastics in Concrete: A Critical Review," Waste Management, vol. 51, pp. 19-42, 2016. 
[5] S. A. Hosseini, "Application of various types of recycled waste materials in concrete constructions," Advances in Concrete Construction, vol. 9, no. 5, pp. 479-489, 2020.

[6] I. I. Chudyk, O. D. Melnyk, O. I. Kirchey, and O. S. Malyshevska, "Some prospects of polymeric wastes usage for preparing lightweight grouting solutions," Scientific Bulletin of UNFU, vol. 27, no. 3, pp. 161-165, 2017.

[7] H. R. Pakravan, M. Latifi, and M. Jamshidi, "Hybrid short fiber reinforcement system in concrete: A review," Construction and Building Materials, vol. 142, pp. 280-294, 2017.

[8] A. Meza, P. Pujadas, L. M. Meza, F. Pardo-Bosch, and R. D. López-Carreño, "Mechanical Optimization of Concrete with Recycled PET Fibres Based on a Statistical-experimental Study," Materials, vol. 14, no. 2, p. 240, 2021.

[9] D. Zhang, J. Yu, H. Wu, B. Jaworska, B. R. Ellis, and V. C. Li, "Discontinuous micro-fibers as intrinsic reinforcement for ductile Engineered Cementitious Composites (ECC)," Composites Part B: Engineering, vol. 184, Article ID 107741, 2020.

[10] A. Babafemi, B. Šavija, S. Paul, and V. Anggraini, "Engineering Properties of Concrete with Waste Recycled Plastic: A Review," Sustainability, vol. 10, no. 11, p. 3875, 2018.

[11] S. W. N Razvi and M. G. Shaikh, "Effect of confinement on behavior of short concrete column," Procedia Manufacturing, vol. 20, pp. 563-570, 2018.

[12] H. M. Afefy and E.-T. M. El-Tony, "Simplified Design Procedure for Reinforced Concrete Columns Based on equivalent Column Concept," International Journal of Concrete Structures and Materials, vol. 10, no. 3, pp. 393-406, 2016.

[13] J. Carrillo, J. Ramirez, and J. Lizarazo-Marriaga, "Modulus of elasticity and Poisson's ratio of fiber-reinforced concrete in Colombia from ultrasonic pulse velocities," Journal of Building Engineering, vol. 23, pp. 18-26, 2019.

[14] Y. Huang and A. Zhou, "Study on Mechanical Properties of PET Fiber-Reinforced Coal Gangue Fine Aggregate Concrete," Geofluids, vol. 2021, pp. 1-13, Article ID 662744, 2021.

[15] R. Sharma and P. P. Bansal, "Use of different forms of waste plastic in concrete - a review," Journal of Cleaner Production, vol. 112, pp. 473-482, 2016.

[16] F. Mahdi, H. Abbas, and A. A. Khan, "Flexural, shear and bond strength of polymer concrete utilizing recycled resin obtained from post consumer PET bottles," Construction and Building Materials, vol. 44, pp. 798-811, 2013.

[17] D. Foti and M. Lerna, "New Mortar Mixes with Chemically Depolymerized Waste PET Aggregates," Advances in Materials Science and Engineering, vol. 2020, pp. 1-9, Article ID 8424936, 2020.

[18] M. Lerna, F. Micelli, A. Cascardi, and M. A. Aiello, "Discontinuous CFRP-jacketing of masonry columns," Key Engineering Materials, vol. 817, pp. 398-403, 2019.

[19] A. Cascardi, M. Lerna, F. Micelli, and M. A. Aiello, "Discontinuous FRP-Confinement of Masonry Columns," Frontiers in Built Environment, vol. 5, p. 147, 2020.

[20] K. Behfarnia and A. Behravan, "Application of high performance polypropylene fibers in concrete lining of water tunnels," Materials \& Design, vol. 55, pp. 274-279, 2014.

[21] I. Shatskyi, I. Popadyuk, and A. Velychkovych, "Hysteretic Properties of Shell Dampers," Dynamic Systems and Applications, vol. 249, pp. 343-350, 2018.

[22] A. Velichkovich, T. Dalyak, and I. Petryk, "Slotted shell resilient elements for drilling shock absorbers," Oil \& Gas Science and Technology - Revue d'IFP Energies nouvelles, vol. 73, p. 34, 2018.

[23] I. P. Shatskyi, V. V. Perepichka, and L. Y. Ropyak, "On the influence of facing on strength of solids with surface defects,"
Metallofizika I Noveishie Tekhnologii, vol. 42, no. 1, pp. 69-76, 2020.

[24] L. Ya. Ropyak, M. V. Makoviichuk, I. P. Shatskyi, I. M. Prytula, L. O. Gryn, and V. O. Belyakovskyi, "Stressed state of laminated interference-absorption filter under local loading," Functional Materials, vol. 27, no. 3, pp. 638-642, 2020.

[25] L. Y. Ropyak, I. P. Shatskyi, and M. V. Makoviichuk, "Analysis of Interaction of Thin Coating with an Abrasive Using OneDimensional Model," Metallofizika I Noveishie Tekhnologii, vol. 41, no. 5, pp. 647-654, 2019.

[26] Y. Y. Striletskyy and V. A. Rovinskyy, "Method of determination of changes of plastic properties of a metal plate by means of frequencies of modes of the string stretched above it," Metallofizika I Noveishie Tekhnologii, vol. 39, no. 10, pp. 1377-1393, 2017.

[27] K. Behfarnia and M. Rostami, "Mechanical Properties and Durability of Fiber Reinforced Alkali Activated Slag Concrete," Journal of Materials in Civil Engineering, vol. 29, no. 12, 2017.

[28] L. S. Saakiyan, A. P. Efremov, L. Y. Ropyak, and A. V. Gorbatskii, "A method of microelectrochemical investigations," Soviet Materials Science, vol. 23, no. 3, pp. 267-269, 1987.

[29] L. S. Saakiyan, A. P. Efremov, and L. Y. Ropyak, "Effect of stress on the microelectrochemical heterogeneity of steel," Protection of Metals, vol. 25, no. 2, pp. 185-189, 1989.

[30] A. V. Buketov, N. A. Dolgov, A. A. Sapronov, and V. D. Nigalatii, "Adhesive Pull and Shear Strength of Epoxy Nanocomposite Coatings Filled with Ultradispersed Diamond," Strength of Materials, vol. 50, no. 3, pp. 425-431, 2018.

[31] N. A. Dolgov, S. N. Romashin, L. Y. Frolenkova, and V. S. Shorkin, "A model of contact of elastic bodies with account for their adhesion," Nanomechanics Science and Technology: An International Journal, vol. 6, no. 2, pp. 117-133, 2015.

[32] A. A. Bedzir, I. P. Shatskii, and V. M. Shopa, "Nonideal contact in a composite shell structure with a deformable filler," International Applied Mechanics, vol. 31, no. 5, pp. 351-354, 1995.

[33] J. Grydzhuk, I. Chudyk, A. Velychkovych, and A. Andrusyak, "Analytical estimation of inertial properties of the curved rotating section in a drill string," Eastern-European Journal of Enterprise Technologies, vol. 1, no. 7 (97), pp. 6-14, 2019.

[34] M. Dutkiewicz, I. Gołębiowska, I. Shatskyi, V. Shopa, and A. Velychkovych, "Some aspects of design and application of inertial dampers," MATEC Web of Conferences, vol. 178, p. 06010, 2018.

[35] I. P. Shats'kyi, "Closure of a longitudinal crack in a shallow cylindrical shell in bending," Materials Science, vol. 41, no. 2, pp. 186-191, 2005.

[36] I. P. Shats'kyi and M. V. Makoviichuk, "Contact Interaction of Crack Lips in Shallow Shells in Bending with Tension," Materials Science, vol. 41, no. 4, pp. 486-494, 2005.

[37] D. A. Panevnik and A. S. Velichkovich, "Assessment of the stressed state of the casing of the above-bit hydroelevator," Neftyanoe Khozyaystvo - Oil Industry, vol. 1, pp. 70-73, 2017.

[38] V. S. Kolesov, N. M. Vlasov, L. O. Tisovskii, and I. P. Shatskii, "The stress-deformation state of an elastic half-space with a spheroidal thermal inclusion," International Applied Mechanics, vol. 28, no. 7, pp. 426-434, 1992.

[39] V. S. Kolesov, N. M. Vlasov, L. O. Tisovskii, and I. P. Shatskii, "The stress concentration in an elastic ball with nonconcentric 
spherical cavity," Journal of Soviet mathematics, vol. 63, no. 3, pp. 335-339, 1993.

[40] A. S. Velichkovich and S. V. Velichkovich, "Vibration-Impact Damper for Controlling the Dynamic Drillstring Conditions," Chemical and Petroleum Engineering, vol. 37, no. 3/4, pp. 213-215, 2001.

[41] A. S. Velichkovich, I. I. Popadyuk, and V. M. Shopa, "Experimental study of shell flexible component for drilling vibration damping devices," Chemical and Petroleum Engineering, vol. 46, no. 9-10, pp. 518-524, 2011.

[42] I. P. Shats'kyi and A. M. Kundrat, "Longitudinal shear of a body with mutually immobile rigid collinear inclusions," Materials Science, vol. 40, no. 3, pp. 376-382, 2004.

[43] I. Shatskyi and I. Kurtash, "Strength of plate with the filled crack under multiparameter loading," Procedia Structural Integrity, vol. 13, pp. 1482-1487, 2018.

[44] M. Lei, D. Lin, C. Shi, J. Ma, and W. Yang, "A Structural Calculation Model of Shield Tunnel Segment: Heterogeneous equivalent Beam Model," Advances in Civil Engineering, vol. 2018, Article ID 9637838, 16 pages, 2018.

[45] T. O. Pryhorovska, "Study on rock reaction force depending on PDC cutter placement," Machining Science and Technology, vol. 21, no. 1, pp. 37-66, 2017.

[46] T. Pryhorovska, "Rock heterogeneity numerical simulation as a factor of drill bit instability," Engineering Solid Mechanics, vol. 6, pp. 315-330, 2018.

[47] I. Shatskyi, A. Velychkovych, I. Vytvytskyi, and M. Seniushkovych, "Analytical models of contact interaction of casing centralizers with well wall," Engineering Solid Mechanics, vol. 7, no. 4, pp. 355-366, 2019.

[48] A. S. Velychkovych, A. V. Andrusyak, T. O. Pryhorovska, and L. Y. Ropyak, "Analytical model of oil pipeline overground transitions, laid in mountain areas," Oil \& Gas Science and Technology - Revue d'IFP Energies nouvelles, vol. 74, p. 65, 2019.

[49] I. Y. Popadyuk, I. P. Shats'kyi, V. M. Shopa, and A. S. Velychkovych, "Frictional interaction of a cylindrical shell with deformable filler under nonmonotonic loading," Journal of Mathematical Sciences, vol. 215, no. 2, pp. 243-253, 2016.

[50] A. S. Velichkovich, "Design features of shell springs for drilling dampers," Chemical and Petroleum Engineering, vol. 43, no. 7-8, pp. 458-461, 2007.

[51] K. Ramujee, "Strength Properties of Polypropylene Fibre Reinforced Concrete," International Journal of Engineering Research and Advanced Technology, vol. 2, no. 8, pp. 34093413, 2013.

[52] J. Zhang, J. Cheng, J. Cheng, Y. Dou, and Q. Xin, "Mechanical Properties and Durability of Fiber-reinforced Concrete," Journal of Engineering Science and Technology Review, vol. 10, no. 5, pp. $68-75,2017$.

[53] Ł. Sadowski, "Adhesion in Layered Cement Composites," Advanced Structured Materials, vol. 101, 2019.

[54] J. Szymanowski, "Evaluation of the Adhesion between Overlays and Substrates in Concrete Floors: Literature Survey, Recent Non-Destructive and Semi-Destructive Testing Methods, and Research Gaps," Buildings, vol. 9, no. 9, p. 203, 2019. 